Review article

\title{
Genetically engineered CAR T-immune cells for cancer therapy: recent clinical developments, challenges, and future directions
}

\author{
Sherien M. El-Daly ${ }^{1,2}{ }^{*}$, Jihan Hussein ${ }^{1}$ \\ ${ }^{1}$ National Research Centre, Medical Research Division, Department of Medical Biochemistry, Dokki, Cairo, Egypt \\ ${ }^{2}$ National Research Centre, Centre of Excellence for Advanced Sciences, Cancer Biology and Genetics Laboratory, Dokki, Cairo, Egypt
}

\section{Abstract}

Cancer immunotherapy offers tremendous clinical outcomes in cancer management with the potential to induce sustained remission in patients with refractory disease. One of these immunotherapy modalities is the adoptive transfer of autologous T-cells that are genetically engineered ex vivo to express chimeric antigen receptors (CARs). These receptors can direct T-cells to the surface antigens of tumor cells to initiate an efficient and specific cytotoxic response against tumor cells.

This review elucidates the structural features of CAR T-cells and their different generations reaching the recent 4th generation (TRUCK). The step-wise treatment process using CAR T-cell therapy and some of the updated prominent clinical applications of this treatment modality in both hematologic and solid malignancies are also covered in the present review. The success of CAR T-cell therapy is still encountered by several limitations for a widespread clinical application of this treatment modality, these challenges along with the recent innovative strategies that have been developed to overcome such drawbacks, as well as, the approaches and future directions aiming for a commercial low cost CAR T-cell immunotherapy modality, are all covered in the present review.
\end{abstract}

Keywords: Adoptive T-cell transfer; CAR T-cells; Cancer immunotherapy; Chimeric antigen receptor; Clinical studies; Toxicity management

\begin{abstract}
Cancer immunotherapy
Cancer immunotherapy is a treatment modality that is evolving quickly with promising results. The mechanism of cancer immunotherapy relies on enhancing an immune response against tumor cells, rather than directly killing cancer cells through radio- or chemical toxicity. Therefore, the aim of this modality is to harness the patient's immune system to fight cancer (Couzin-Frankel, 2013; Morrow, 2017). Cancer immunotherapies are classified as active and passive methods; the active method promotes the effective anti-tumor mechanisms to improve cancer elimination by vaccination or adjuvant therapy. On the other hand, the passive method involves either the administration of monoclonal antibodies directed toward specific tumor antigens or the adoptive transfer of modified T-cells (Stanculeanu et al., 2016). Adoptive cell transfer (ACT) or the cell-based therapy implies collecting and using patients' own immune cells to fight their own cancer cells, so far, the one that is proved to be successful in clinical applications and most rapidly developing is the CAR T-cell therapy. As obvious from the name, the backbone of CAR T-cell therapy is the use of T-cells which are known as the workhorses of the immune system (Houot et al., 2015).
\end{abstract}

\section{Chimeric antigen receptor (CAR) T-cells}

T-cells are genetically modified to increase their targeting efficiency toward tumor cells through the expression of a chimeric antigen receptor (CAR) on their cell surface, producing what is known as CAR T-cells. This process is currently the most rapidly developing approach in cancer adoptive cellular immunotherapy. CAR T-cells are engineered cells expressing synthetic receptors that can efficiently redirect T-cells to surface antigens for subsequent tumor elimination through the cytotoxic effect of T-cells (Lipowska-Bhalla et al., 2012). CAR T-cells typically consist of a single-chain variable fragment ( $\mathrm{scFv}$ ), which is an antigen-binding moiety of a monoclonal antibody specific for a tumor cell-surface marker. This variable domain is linked to the constant region of the T-cell receptor (TCR) (Fig. 1) (Zhang et al., 2017).

This simplest form of CAR T-cells was first developed in 1989 (Gross et al., 1989). Following this date, many efforts have been made to develop and improve the recognition specificity of T-cells toward tumor associated antigens (TAAs) and also improve the proliferative and cytotoxic efficiency of these genetically engineered cells.

\footnotetext{
* Author for correspondence: Sherien M. El-Daly, National Research Centre, Medical Research Division, Department of Medical Biochemistry, 33 El Buhouth St., Dokki, 12622 Cairo, Egypt; e-mail: sm.el-daly@nrc.sci.eg; sherien_eldaly@yahoo.com http://doi.org/10.32725/jab.2019.005

Submitted: 2018-08-30 • Accepted: 2019-01-29 • Prepublished online: 2019-02-20

J Appl Biomed 17/1: 1-11 • EISSN 1214-0287 • ISSN 1214-021X

(c) 2019 The Authors. Published by University of South Bohemia in České Budějovice, Faculty of Health and Social Sciences.

This is an open access article under the CC BY-NC-ND license.
} 


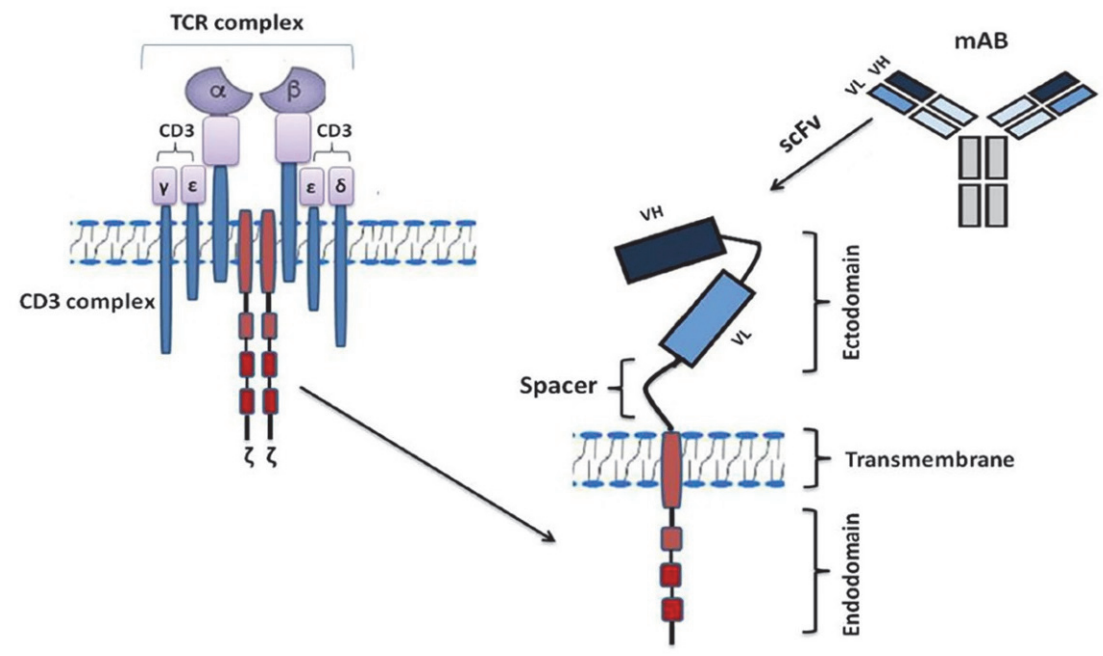

Fig. 1. Structural components of T-cell receptor (TCR) and monoclonal antibody (mAb) used in the construction of a CAR. Basic structure of chimeric antigen receptor CAR T-cell consists of an antigen binding ectodomain, commonly derived from a single chain variable fragment ( $\mathrm{scFv}$ ) of a mAb, a transmembrane domain, and a signalling endodomain.

\section{Structural design of CAR T-cells}

The structural pattern of CAR T-cells typically consists of an extracellular antigen recognition domain (ectodomain), a trans-membrane hinge domain that connects the CAR to the cell membrane, and one or more intracellular signalling endodomains (Fig. 1).

\section{The ectodomain (targeting moiety)}

The ectodomain is the domain outside the cytoplasm exposed to the extracellular space. The domain is derived from a single chain variable fragment ( $\mathrm{scFv}$ ) of a monoclonal antibody that targets a specific tumor antigen, therefore the ectodomain is considered as the antigen recognition region of CAR T-cells (Srivastava and Riddell, 2015). The scFv can recognize the TAA expressed on tumor cells independently of the classical antigen processing and presentation by the major histocompatibility (MHC) complex, which is considered as one of the main characteristics of CAR T-cells. The potential target-molecules are not restricted to peptide antigens, but rather a wide range of surface marker molecules that are uniquely expressed on tumor cells including glycolipids, glycoproteins, and gangliosides can all be used as targeting molecules (Wang and Rivière, 2016).

\section{The hinge region (Spacer)}

The connection between the ectodomain and the trans-membrane domain relies on the hinge part (spacer); the most sufficient and simplest form of spacer is the hinge region of IgG1. The hinge region affects the flexibility of the ectodomain therefore it is important for ensuring the suitable positioning of the antigen binding domain during antigen-CAR interaction process. The length of the hinge region could affect the quality of interaction between the T-cell and its target. The optimum distance required is likely to be different for each antigen (Qin et al., 2017).

\section{The trans-membrane domain}

Between the spacer and the signalling end domains, lies the trans-membrane domain (Fig. 1). The trans-membrane domain consists of a hydrophobic alpha helix that extends over the membrane. Several studies have suggested that the sta- bility of CAR is related to the trans-membrane domain. Most CAR T-cells include a trans-membrane domain derived from type I membrane proteins, such as $\mathrm{CD} 3 \zeta, \mathrm{CD} 8, \mathrm{CD} 4$, or CD28. Currently, CD28 trans-membrane domain is considered as the most stable receptor (Dotti et al., 2014).

The endodomain (signalling domain)

The endodomain is the functional part of CAR T-cells responsible for T-cells activation, proliferation, and survival. Upon antigen recognition by the ectodomain, CAR endodomain transmits co-stimulatory signals to T-cells to start their cytotoxic action. The structure of the CAR endodomain has been the main subject of many modifications and improvements in an effort to improve the functionality and efficacy of CAR T-cells (Li and Zhao, 2017).

\section{Generations of CAR T-cells (based on endodomains)}

For an efficient and optimal activation of T-cells; two distinct signals are required. Signal 1 is provided by the binding of the TCR expressed on T-cells with the foreign peptide presented by the MHC complex. Signal 2 is provided by the binding of the co-receptor protein CD28 expressed on the T-cell surface with the co-stimulatory B7 molecules [B7.1 (CD80) or B7.2 (CD86)] expressed on antigen-presenting cells. The function of signal 2 is to amplify the intracellular signaling triggered by signal 1 . If T-cell received signal 1 without signal 2, it could undergo apoptosis or become non efficient so that it can no longer be activated. Therefore, signal 1 and signal 2 are both necessary for the optimal activation and effective function and survival of T-cells (Chen and Flies, 2013). Based on this mechanism of action, the procedure of CAR T-cell construction yielded four generations of CAR T-cells based on the structure of the endodomain (Fig. 2).

First generation of CAR T-cells

The structure of the first generation of CAR T-cells consisted of $\mathrm{scFv}$ joined to a single structure intracellular signalling domain $\mathrm{CD} 3 \zeta$. This structure was only able to provide signal 1 required for T-cell activation with modest cytokine secretion. However, as mentioned before, T-cells cannot functionally perform their cytotoxic effect if the co-stimulatory signal 2 is absent. There- 


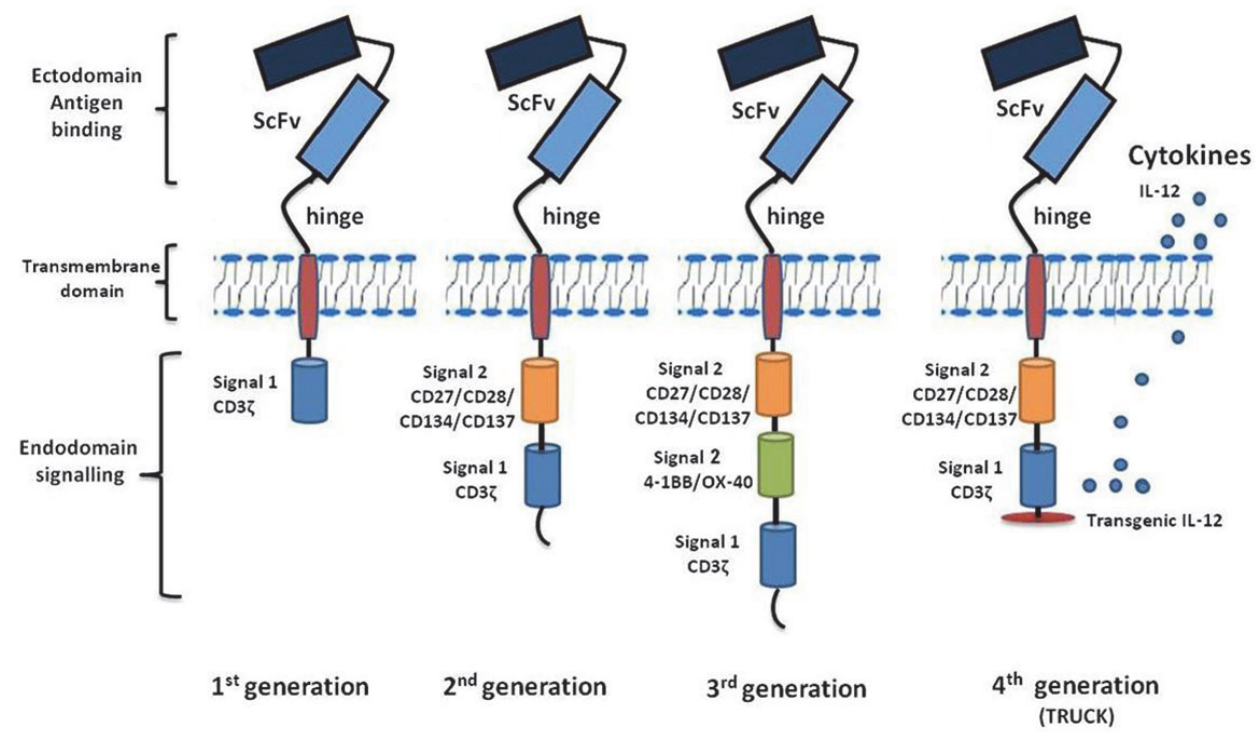

Fig. 2. Schematic representation elucidating the different generations of CAR T-cells

First generation of CAR T-cells contains single signaling module $\mathrm{CD} 3 \zeta$, while second and third generations contain one or two additional co-stimulatory domains to enhance the survival as well as proliferation and persistence of activated CAR T-cells. The 4th generation (TRUCK) is the newest approach in adoptive T-cell therapy, where CAR T-cells are genetically modified with an inducible cytokine gene cassette to immediately secrete cytokines such as IL-12 upon CAR T-cell activation.

fore, first generations of CAR T-cells were not effective with very weak proliferation ability and high apoptotic potential (Cheadle et al., 2014).

\section{Second generation of CAR T-cells}

To improve limitations of the first generation of CAR T-cells, the second-generation involved the addition of two intracellular signalling domains from various co-stimulatory protein receptors (such as CD28) to the cytoplasmic tail of the CAR T-cells. The interaction between the intracellular signalling domain CD28 and the B7 family molecules (B7.1 or B7.2) found on the sur $\neg$ face of tumor cells is efficient to provide the second activation signal that enhances signal 1 from the TCR-CD3 $\zeta$ complex, and therefore improves the sustained proliferation of CAR T-cells. Eventually this will enhance the production of cytokines and granulocytes and improve the cytotoxic activity of these engineered cells (Ritchie et al., 2013). In the study by Brentjens et al. (2007), the treatment of acute lymphoblastic leukemia using the second-generation CAR T-cells containing signalling domain of the CD28 receptor increased the eradication efficiency compared to the use of the first-generation CAR T-cells.

\section{Third generation of CAR T-cells}

In the effort to improve CAR T-cell design for a more eradication efficiency, the third generation of CAR T-cells was developed. In this form, three co-stimulatory domains were added in order to offer signal 1, signal 2, and another co-stimulatory signal to boost T-cell activation signals. These multiple signal-

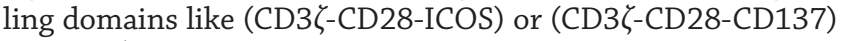
or (CD3 $\zeta-C D 28-O X 40)$ could improve the survival of engineered T-cells and provide a much stronger cytokine production and anti-tumor cytotoxic effect. In the study by Pulè and his colleagues (Pulè et al., 2005), the signalling domains (CD28 followed by OX40 followed by $\mathrm{CD} 3 \zeta$ ) produced sustained activation, proliferation and improved the production of the cytokines IL-2 and TNF- $\alpha$ and hence efficiently enhanced the cytolytic activity of the engineered T-cells compared to the second generation of CARs with only the signalling domains

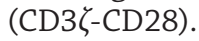

Fourth generation of CAR T-cells

The fourth generation of CAR T-cells, also known as T-cells redirected for universal cytokine killing (TRUCKs) is generated by adding a transgenic cytokine like interlukin-12 (IL-12) to the base of a second-generation constructs (Chmielewski and Abken, 2015). IL-12 is a pleiotropic cytokine that could provide potent anti-tumor responses through stimulating the immune system (Choo et al., 2009). Interaction between fourth-generation CAR T-cells and their target antigens will cause activation of these cells and simultaneous secretion of cytokines like IL-12 in the target tissue, accumulation of IL12 can effectively attract innate immune cells mainly natural killer cells and macrophages to the tumor microenvironment in an effective way to initiate a second wave of immune cells in order to attack and kill other tumor cells which were not recognized by the CAR T-cells due to the lack of the CAR-recognized target on their surface (Chmielewski and Abken, 2015; Zhang et al., 2017).

\section{Selection of the target antigen}

The most important challenge in the production of the ideal CAR construct is choosing the appropriate target associated antigens (TAA). Ideally, engineered CAR T-cells should target only tumor cells away from normal cells, but actually the expression of most TAAs is not restricted to tumor cells and unique tumor antigens are rare to be found (Shirasu and Kuroki, 2012). Tumor cells are mainly derived from normal cells and most of the identified TAAs are self-antigens, the only difference is that TAAs are usually over-expressed in tumor cells but low expressed in normal cells. Antigens arising from gene mutations could be the ideal targets for CAR construct since such targets are not expressed on normal tissue cells. Unfortunately, not all tumors express specific mutations with common genetic alterations that could be targeted (Chmielewski et al., 2013; Li and Zhao, 2017). Therefore, choosing the right 
target is a critical point in CAR-T construction not only for enhancing the targeting specificity but also for patients' safety. The B-lymphocyte antigens CD19 and CD20 are validated targets that are widely used in CAR T-cell therapy for CD19- and CD20-positive hematologic malignancies. CD19-CAR T-cells and CD20-CAR T-cells have been successfully applied in several clinical trials to treat chronic lymphocytic leukemia (CLL), acute lymphoblastic leukemia (ALL), diffuse large B cell lymphoma (DLBCL), and B-cell non-Hodgkin lymphoma (B-NHL) (Chu et al., 2015; Hartmann et al., 2017; Martyniszyn et al., 2017). Examples of other antigens that have been used for the construction of CAR T-cells targeting hematologic malignancies/solid tumors are summarized in Table 1.

Table 1. List of some tumor associated antigens that have been used in different clinical trials of CAR T-cells application with different levels of success and efficacy

\begin{tabular}{|c|c|}
\hline Target antigen & Tumor type \\
\hline CD22 & $\begin{array}{l}\text { B-cell acute lymphoblastic leukemia (Haso et } \\
\text { al., 2013) }\end{array}$ \\
\hline CD30 & $\begin{array}{l}\text { Hodgkin lymphoma (Di Stasi et al., 2009; } \\
\text { Ramos et al., 2017; Wang et al., 2017) }\end{array}$ \\
\hline CD33 & $\begin{array}{l}\text { Acute myeloid leukemia (Kenderian et al., } \\
\text { 2015; Li et al., 2018; Minagawa et al., 2016) }\end{array}$ \\
\hline $\begin{array}{l}\text { Estrogen-related } \\
\text { receptor beta type } 2 \\
\text { (ERRB2) }\end{array}$ & $\begin{array}{l}\text { Breast cancer (Teng et al., 2004) } \\
\text { Prostate cancer (Pinthus et al., 2003) }\end{array}$ \\
\hline $\begin{array}{l}\text { Prostate-specific } \\
\text { mem-brane antigen } \\
\text { (PSMA) }\end{array}$ & $\begin{array}{l}\text { Prostate cancer (Junghans et al., 2016; Maher } \\
\text { et al., 2002; Zuccolotto et al., 2014) }\end{array}$ \\
\hline $\begin{array}{l}\text { Carbonic anhydrase IX } \\
\text { (CAIX) }\end{array}$ & Renal cell carcinoma (Lamers et al., 2006) \\
\hline $\begin{array}{l}\text { Carcinoembryonic } \\
\text { antigen (CEA) }\end{array}$ & Colon cancer (Sheen et al., 2003) \\
\hline $\begin{array}{l}\text { Mesothelin surface - } \\
\text { glycoprotein }\end{array}$ & $\begin{array}{l}\text { Malignant pleural mesothelioma (Mayor } \\
\text { et al., 2016), Ovarian cancer (O’Hara et al., } \\
\text { 2016), pancreatic adenocarcinoma (Beatty et } \\
\text { al., 2014), breast cancer (Tchou et al., 2012) }\end{array}$ \\
\hline
\end{tabular}

\section{Procedure of CAR T-cell therapy in the clinic}

The process of CAR-T production and patient treatment is a sophisticated procedure that requires several carefully per- formed steps, and a continuous quality control evaluation throughout the entire procedure. The procedure can be summarized in the following steps (Fig. 3):

1. Collecting T-cells from the patient: Patient's T-cells are collected via a procedure called leukapheresis. In this procedure, the blood of the patient is withdrawn and the leukocytes are collected while the remaining components of the blood are infused back into the circulation. Separation of T-cell (CD4+/CD8+ composition) are conducted using specific antibody bead conjugates for T-cells enrichment (Maus and June, 2016).

2. Reengineering of $\mathbf{T}$-cells in the laboratory: The collected $\mathrm{T}$ cells (CD4+/CD8+ composition) are then sent to a laboratory where they are cultured to be genetically engineered for the production of CARs on their surfaces. In this process, isolated T-cells are transfected with a viral vector (such as $\gamma$-retroviral or lentiviral) encoding genes for the desired CAR construct. The virus fuses with the cell membrane of the isolated T-cells and introduces the genetic material in the form of RNA. The RNA is then reverse-transcribed into DNA and permanently integrates into the genome of the isolated patient cells; therefore, CAR expression is maintained as the cells divide and expand to large numbers in culture. Lentiviral vectors are commonly used than $\gamma$-retroviral vectors because of their safe integration site profile. Following the expansion in the number of the engineered CAR T-cells in vitro, these CAR T-cells are then frozen and sent to the hospital where the patient is under treatment ( $\mathrm{Li}$ and Zhao, 2017; Morgan and Boyerinas, 2016).

3. Infusing CAR T-cells into the patient: At the hospital and prior to infusion of the CAR T-cells, the patient is given a brief course of chemotherapeutic agents, in a process called "lymphodepletion" to avoid possible rejection of the infused CAR T-cells through reduction of $\mathrm{T}$ regulatory cells (Treg) in the lymphoid tissues and in tumor (Yao et al., 2012). Early studies using CAR T-cells with no prior lymphodepletion step, resulted in short persistence and poor antitumor activity of the infused cells (Gattinoni et al., 2005). CAR T-cells that have been returned to the patient's blood circulation are considered as the "attacker" cells that could recognize and attack cells that have the targeted antigen on their surface.

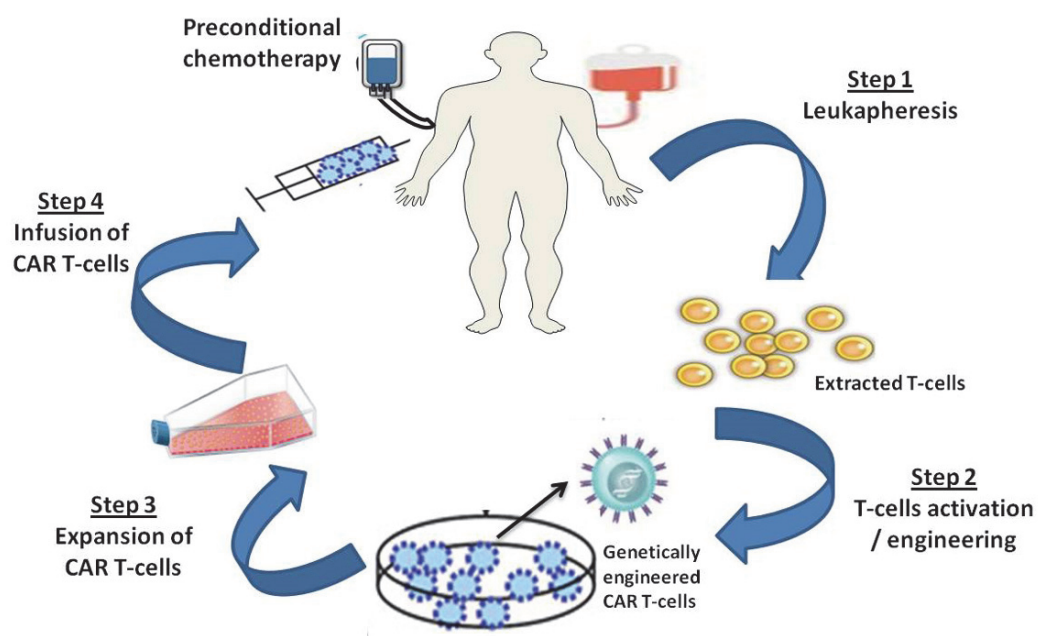

Fig. 3. A diagram presenting the steps of CAR T-cell therapy procedure in clinic 


\section{Advantageous characteristics of CAR T-cell immunotherapy}

The use of CAR T-cells has several privileges over other cancer immunotherapy modalities. These advantages are summarized as follow:

1. One of the greatest benefits of this technique is that the chimeric receptors ensure this therapy is a targeted therapy. Moreover, CAR T-cells are live cells so they are expected to expand in the patient for the establishment of an immune memory, providing continuous surveillance to target localized and metastatic lesions (Hartmann et al., 2017).

2. The use of CARs is applicable to a broad range of patients irrespective of the MHC complex type, as the mechanism of interaction is not restricted to the antigen presentation by the MHC molecule. In CAR T-cell application, the interaction between CAR and the antigen ligand differs from that which occurs between a normal T-cell receptor and its antigen peptide-MHC ligand where the affinity and avidity in the first case are much higher. This feature enables the engineered T-cells to overcome the tumor's ability to escape from immune recognition through down-regula $\neg$ tion of MHC molecules on tumor cell surface (Farkona et al., 2016).

3. Genetically modified T-cells could effectively target a wide range of molecules in comparison with native-TCR, since targeting molecules in case of CAR-T therapy are not restricted to antigen peptides expressed on tumor cells, rather any surface markers uniquely or abundantly expressed on tumor cells can be used. Specific glycolipids, glycoproteins, and gangliosides can all be used as targeting molecules (Lo et al., 2010; Wang and Rivière, 2016).

4. The engineering process of CAR T-cells can involve one or more T-cell activating signalling domains which will be associated with a high proliferation and persistence potential of T-cells in the tumor microenvironment, and eventually effective cytotoxic potential (Pulè et al., 2005).

\section{Clinical trials of CAR T-cell immunotherapy}

Early clinical trials applying first generation of CAR T-cells did not demonstrate remarkable response; however encouraging clinical outcomes have been reported only with the application of the second and third generation of CARs (Hartmann et al., 2017). In the following section a brief summary of some of the prominent clinical trials using CAR T-cells in different cancer types is presented.

\section{CAR T-cell immunotherapy for hematologic malignancies} Although hematological malignancies represent a relatively small part of the total cancer burden, they have been presented as the ideal types with high responsive rates for cancer immunotherapy. In case of CAR T-cell therapy, the most promising results have been reported from the clinical trials on B-cell malignancy patients (Gauthier and Yakoub-Agha, 2017). Most of the published clinical trials of CAR T-cell therapy for hematological malignancies involved the usage of a CD19-target moiety. CD19 is a B-cell surface protein that is highly overexpressed on all B-cell malignancies, therefore CD19 is considered as an attractive target for immunotherapy (Sadelain, 2017). The initial trials using the second generation of CD19-directed CAR T-cells were applied on small number of patients diagnosed with ALL or refractory CLL, however, the results were impressive with a complete remission (Brentjens et al., 2011; Grupp et al., 2013; Porter et al., 2011) which encouraged for further clinical trials. These results were later supported by a series of clinical trials describing larger number of patients with
B-cell malignancies receiving CD19-directed CAR T-cell therapy (Brentjens et al., 2013; Davila et al., 2014; Maude et al., 2014; Turtle et al., 2017). In all these studies, there were several differences between the treated groups (e.g. the patients population, the type of B-cell malignancy, the engineering technique used for the construction of CAR T-cells, and the application or not of the lymphodepletion step), however several remarks were observed (Gill and June, 2015). These remarks can be summarized as following: (1) second generation of CAR T-cells were superior to first generation; (2) patients that received a lymphodepleting chemotherapy protocol prior to the infusion of CAR T-cells reported better results; (3) patients with ALL showed better response than patients with CLL; (4) patients with high response rate suffered severe cytokine release syndrome; (5) no dose-response relationship could be related to the number of infused CAR T-cells and the response magnitude; (6) no significant correlation could be detected between initial tumor burden and response (Gill and June, 2015). An interesting observation has been reported in few patients who initially responded very well to the treatment using CD19-directed CAR-T but then suffered from a relapse with CD-19 negative tumor cells. This could be an indication for the ability of progressive tumor cells to rapidly initiate an immune escape however, no much reports of such a case are observed in the different clinical trials (Grupp et al., 2013). Other prominent clinical trials of CAR T-cell immunotherapy for different hematologic malignancies are presented in Table 2.

\section{CAR T-cell immunotherapy for solid tumors}

Clinical trials using CAR T-cells to target solid tumors have not achieved the same response seen in hematological malignancies (Xu et al., 2017). The reduced efficacy of the CAR T-cell immunotherapy in solid tumors is attributed to various factors. For example; the complex structure of the microenvironment of the solid tumor (immune cells, fibroblasts, extracellular matrix molecules, cytokines, endothelial cells, stellate cells) would hinder the access and trafficking of CAR T-cells and would also affect their efficacy, unlike the hematological malignancies (Scarfò and Maus, 2017). Hypoxia (low oxygen availability) of solid tumor microenvironment, which is a hallmark of most solid tumors, also negatively affects the efficiency of CAR T-cells. However, in the study by (Hatfield et al., 2015) it is reported that respiratory hyperoxia reduced the intra-tumoral hypoxia and as a result increased the production of pro-inflammatory cytokines, decreased the immunosuppressive molecules, and most importantly enhanced the intra-tumoral infiltration of CAR T-cells. Subsequently, hyperoxia improved tumor regression, supporting the suggestion that oxygen supplementation should be accompanied with CAR-T therapy for a more potent effect.

Solid tumor cells are also characterized by the over-expression of immune checkpoint ligands such as programmed death-ligand 1 (PD-L1) that could bind to the $\mathrm{PD}-1$ receptors expressed on T-cells and thus reduce the cytotoxic effect of T-cells. Therefore, it was suggested that a combination of CAR T-cells and PD-1 blockade should be considered to improve the effect of CAR T-cell therapy in solid tumor (Chong et al., 2017; John et al., 2013).

The other concern that is also highlighted in solid tumor is the on-target/off-tumor toxicity (this point will be explained in detail later in the toxicity section). Most of the targeting moieties that have been used in CAR construct to target solid tumor cells are also expressed at low levels on the surface of normal cells. This problem is less common in hematological malignancies (Xu et al., 2017). In a trial using first generation 
Table 2. List of some published clinical trials of CAR T-cell immunotherapy for different hematologic and solid malignancies

\begin{tabular}{|c|c|c|c|c|c|}
\hline Tumor target & Type of tumor & Signalling domain & No. of cases & Clinical efficacy & Clinical trial gov. identifier \\
\hline CD-19 & ALL & 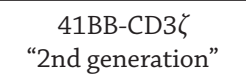 & 30 & $\begin{array}{l}27 \text { complete remission } \\
3 \text { progressive disease }\end{array}$ & $\begin{array}{l}\text { NCT01626495 } \\
\text { NCT01029366 }\end{array}$ \\
\hline CD-19 & ALL & $\begin{array}{c}\text { CD28-CD3 } \\
\text { "2nd generation" }\end{array}$ & 16 & $\begin{array}{l}14 \text { complete remission } \\
2 \text { progressive disease }\end{array}$ & NCT01044069 \\
\hline CD-19 & $\begin{array}{c}\text { CLL + } \\
\text { ALL }\end{array}$ & 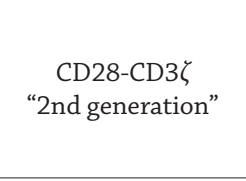 & $\begin{array}{l}8 \mathrm{CLL} \\
2 \mathrm{ALL}\end{array}$ & $\begin{array}{c}1 \text { complete remission } \\
1 \text { partial remission } \\
2 \text { stable disease } \\
4 \text { progressive disease } \\
2 \text { non evaluable }\end{array}$ & $\begin{array}{l}\text { NCT00466531 (CLL) } \\
\text { NCT01044069 (ALL) }\end{array}$ \\
\hline $\mathrm{CD} 20$ & DLBCL & $\begin{array}{c}41 \mathrm{BB}-\mathrm{CD} 3 \zeta \\
\text { "2nd generation" }\end{array}$ & 7 & $\begin{array}{c}1 \text { complete remission } \\
4 \text { partial remission } \\
1 \text { progressive disease } \\
1 \text { non evaluable }\end{array}$ & NCT01735604 \\
\hline $\mathrm{BCM}$ & Multiple Myeloma & $\begin{array}{c}\text { CD28-CD3 } \\
\text { "2nd generation" }\end{array}$ & 12 & $\begin{array}{l}\text { Overall response rate } \\
33 \%\end{array}$ & NCT02215967 \\
\hline GD2 & Neuroblastoma & $\begin{array}{c}\mathrm{CD} 3 \zeta \\
\text { "1st generation" }\end{array}$ & 19 & $\begin{array}{c}3 \text { complete remission } \\
1 \text { partial remission } \\
1 \text { stable disease } \\
6 \text { progressive disease } \\
8 \text { non evaluable }\end{array}$ & $\begin{array}{l}\text { NCT00085930 } \\
\text { NCT02546167 }\end{array}$ \\
\hline CAIX & Renal cell carcinoma & $\begin{array}{c}\mathrm{CD} 3 \zeta \\
\text { "1st generation" }\end{array}$ & 12 & none & $\begin{array}{c}\text { DDHK97- } \\
\text { 29/P00.0040C }\end{array}$ \\
\hline HER2 & Colon carcinoma & $\begin{array}{l}\text { CD28-41BB-CD3 } \\
\text { "3rd generation" }\end{array}$ & 1 & none & NCI-09-C-0041 \\
\hline HER2 & Sarcoma & $\begin{array}{c}\text { CD28-CD3 } \\
\text { "2nd generation" }\end{array}$ & 19 & $\begin{array}{l}4 \text { stable disease } \\
15 \text { none }\end{array}$ & NCT00902044 \\
\hline
\end{tabular}

of CAR T-cells to treat patients with renal carcinomas, carbonic anhydrase-IV (CAIX) which is over-expressed on renal carcinomas cells was used as the target moiety in CAR T-cell construct (Lamers et al., 2006). However, since CAIX is also expressed at low levels on the epithelial cells of the bile duct, a significant hepatotoxicity was reported in the patients and the therapy was discontinued (Lamers et al., 2013).

In the search to improve CAR T-cell treatment modality in solid tumor, several innovative strategies are suggested to reduce the immunosuppressive effects of the solid tumor microenvironment, to address the intra-tumoral metabolic challenges, and to choose the accurate target antigen in order to enhance the success of CAR T-cell therapy in solid tumors (Chmielewski et al., 2014; Nishio et al., 2014; Scarfò and Maus, 2017).

\section{Limitations and challenges of using CAR T-cells}

Toxicity that could evolve from CAR T-cell therapy is considered the main limitation hindering the wide clinical application of this treatment modality. There are several types of toxicities and they can be summarized as follow:

\section{Anaphylaxis (Antigenicity problem)}

The majority of the engineered CAR T-cells reported so far have an ectodomain ( $\mathrm{scFv}$ ) derived from mice or humanized antibodies for the recognition of tumor associated antigen, this could trigger a host immune response with risks for the production of human anti-mouse antibodies (HAMA), which could limit the efficiency of CAR T-cells. Therefore, most of the research now is focusing on synthesizing CAR T-cells with full human antibodies, in a way to reduce immunogenicity response (Bonifant et al., 2016).
Toxicity from the gene delivery system (insertional mutagenesis) During the engineering process of CAR T-cells, viral vectors $(\gamma$-retroviral or lentiviral) are used to express CARs on isolated T-cells, however the insertion of a transgene into T-cells may carry the risk of induced insertional mutagenesis that might lead to oncogenesis. Although this toxicity risk is still a hypothetical concern, the recent research interest is focusing on developing alternative vector systems that could maintain efficient genomic integration capacity while cost-effective. Sleeping Beauty (SB) transposon vectors could fulfil these requirements and additionally overcome limitations associated with the viral gene transfer vectors. Transposon vectors offer high stable gene transfer with sustained transgene expression (Hackett et al., 2013; Morgan and Boyerinas, 2016).

\section{On-target / off-tumor toxicity}

This type of toxicity is attributed to the fact that most of the TAA could also be found at low levels on normal cells. Therefore, targets of CAR T-cells expressed on normal tissue cause what is called "on-target/off-tumor" toxicity (Fisher et al., 2017). This type of toxicity could range from manageable B-cell aplasia to severe toxicity and death. An example of this kind of toxicity is the severe transient colitis that has been detected in colon cancer patients treated with CAR T-cells targeting carcinoembryonic antigen (CEA). This toxicity was attributed to the possibility that normal colonic tissue that express CEA was also targeted by CAR T-cells (Parkhurst et al., 2011). A fatal example of the "on-target/off-tumor" toxicity was reported in a case study where a patient treated with CAR T-cells targeting ERBB2 antigen developed a rapid respiratory failure, multi-organ dysfunction, and subsequent death after 5 days of treatment. The fatality in this case was attributed to the reactivity 
of CAR T-cells against healthy pulmonary tissue expressing ERBB2 (Morgan et al., 2010). To prevent or reduce this type of toxicity, the accurate selection of antigen is required with a careful monitoring dose of CAR T-cells (Bonifant et al., 2016).

Cytokine release syndrome (CRS)

This kind of toxicity is the most challenging side effect following CAR T-cells injection and is attributed to the rapid activation of CAR T-cells following infusion in the blood circulation of the patient, causing general perturbation of the immune system and a sudden release of pro-inflammatory cytokines, mostly interleukin-6 and IFN- $\gamma$ (Xu and Tang, 2014). The symptoms of CRS include fever, fatigue, myalgia and headache. Few patients were reported to suffer from severe symptoms leading to multisystem organ failure. To control this type of toxicity, the injected dose of CAR T-cells is modified and the use of interleukin- 6 blockade (anti-interleukin- 6 antibody, tocilizumab) is reported to be the front-line treatment option for CRS following CAR T-cells infusion (Maude et al., 2014).

\section{Neurological toxicity}

Neurologic toxicities such as confusion, aphasia, seizure, and delirium have been reported in few patients following treatment with CD19-CAR T-cells. This kind of toxicity could be attributed to the sudden elevation in the cytokine levels, however the exact mechanisms of these neurologic disorders are not yet clearly known. It should be mentioned that these symptoms have been reported to be reversible in the majority of cases (Bonifant et al., 2016).

\section{Toxicity management and optimizing CAR T-efficiency}

Management of CAR T-cell toxicities is considered as the major critical step for a successful clinical application of this treatment modality. Few innovative techniques have been suggested and applied to reduce toxicity (Bonifant et al., 2016).

\section{Suicide genes}

In a way to control the toxicities associated with CAR-T therapy, engineering of CAR T-cells that can express a suicide gene is considered as a promising managing technique that is cur- rently under intense evaluation in several clinical trials. The most successful and clinically validated suicide gene is reported to be the inducible caspase-9 (iCasp9) gene. The dimerizable iCasp9 is incorporated in engineered CAR T-cells containing the intracellular part of the pro-apoptotic molecule caspase-9, which is fused to a drug-binding domain derived from human FK506- binding protein (Fig. 4). Selective depletion of the genetically modified CAR T-cells can be initiated by the intravenous administration of a small, bio-inert, chemical inducer of dimerization (CID) drug AP1903. This drug will cross-link with the drug binding domain and initiate dimerization of the infused caspase- 9 leading to activation of the downstream executioner caspases and eventually induction of CAR T-cells apoptosis (Jones et al., 2014). A single low dose of the dimerizing agent (AP1903) was able to eliminate almost $90 \%$ of iCasp9-modified CAR T-cells after 30 minutes of administration (Di Stasi et al., 2011; Zhou et al., 2014). This suicide gene system is known as CaspaCIDe ${ }^{\circledR}$.

\section{Enhancing targeting specificity}

Controlling the "on-target/off tumor" toxicity could be possible through the inclusion of what is called "on-switch" in the design of CAR T-construct. In this case, the response of T-cell is controlled through a combinatorial targeting of two antigens with separation of T-cell activation signals. This requires the recognition of two target antigens co-expressed on tumor cell in order to initiate a CAR T-cell response. In this case, dual-antigen binding is necessary for a complete cytotoxic effect of CAR T-cells while normal cells expressing only one target antigen will not be efficient to activate CAR T-cells (Jaspers and Brentjens, 2017; Li and Zhao, 2017). On contrary, if expression of dual antigens is exclusive to normal cells, inclusion of inhibitory signalling in CAR T-cell construct allows for selective targeting of tumor cells expressing only one antigen while normal cells are excluded (Fisher et al., 2017).

Improving the persistence of CAR T-cells

Genetically engineered $\mathrm{T}$ cells should survive for enough time to perform efficient cytotoxicity toward tumor cells. Therefore, the efficacy of CAR T-cells is primarily correlated with the

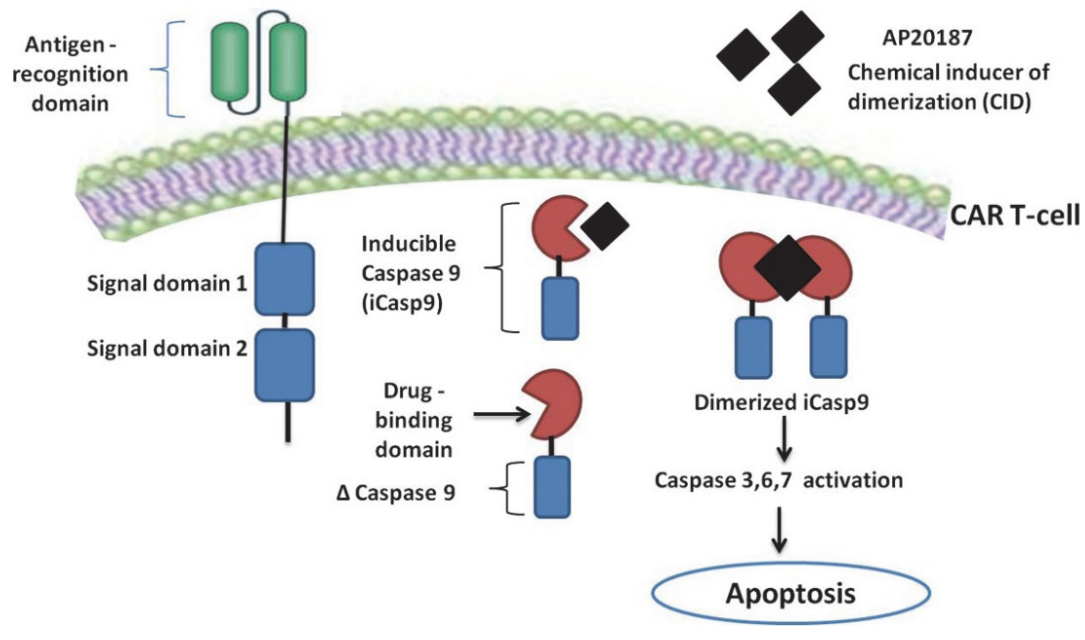

Fig. 4. CAR T-cell with "off switch" suicide gene (CaspaCIDe $\left.{ }^{\circledR}\right)$ to initiate apoptosis of CAR T-cell when required. Inducible caspase 9 (iCasp9) is coexpressed in the genetically modified T-cell as a homodimer with a drug-binding domain. Once a chemical inducer of dimerization (AP20187 or AP1903) is administered this will result in dimerization of caspase-9 leading to an activated form of the molecule, which in turn initiates a caspase signaling cascade and eventually initiates apoptosis of the CAR T-cell. 
persistence of these engineered cells in the blood circulation and the tumor microenvironment (Li and Zhao, 2017; Scarfò and Maus, 2017). Most of the clinical studies that applied first generation of CAR T-cells have attributed the failure and low response rate to the poor persistence of the first-generation of CAR T-cells. To overcome these drawbacks the second and third generation of CAR T-cells have been modified to increase the persistence of these genetically engineered cells through addition of two or more co-stimulatory domains (Carpenito et al., 2009; Milone et al., 2009). Another procedure that can also enhance the persistence of CAR T-cells is the lymphodepleting step (Conditioning chemotherapy) prior to the infusion of CAR T-cells. As mentioned before, this step will remove suppressive cells like T-regulatory cells and myeloid cells and hence increase the persistence of CAR T-cells ( $\mathrm{Li}$ and Zhao, 2017).

Adoptive transfer of viral-specific cytotoxic T-lymphocytes (CTLs) that are genetically modified to express CAR is a successful approach for long-time persistent CAR T-cells (i.e. Epstein-Barr virus- or Adenovirus-specific T cells). An increased persistence of CAR T-cells in the blood circulation have been detected in neuroblastoma patients that have been injected with EBV-CTLs expressing GD2-CARs compared to activated T-cells expressing GD2-CAR, this difference could be attributed to the superior co-stimulation of CAR-CTLs provided when the cells engaged EBV antigens on antigen-presenting cells through their native receptors (Louis et al., 2011; Pule et al., 2008).

\section{Future direction "Universal CAR T-cells"}

There is considerable progress in adoptive cell therapies using engineered CAR T-cells, which is considered as a highly personalized cancer therapy. However, there are few barriers that are still limiting its clinical applications. Long time is required to collect T-cells, conduct genetic modification, allow expansion of the engineered cells, and reintroduce CAR T-cells into the patient. This long-time manufacturing process can be problematic for patients. Additionally, the high expense to produce individualized product for each patient is also a problem (Hartmann et al., 2017). Novartis (the company that received the FDA approval for the first approved CAR T-cell therapy under the name of Kymriah) is going to introduce this treatment modality for each patient at a price of almost $\$ 475,000$ for a single infusion. Therefore, the interest of many research groups has been focused on reducing the required starting material and eventually the total production time. This has lead to the development of universal targeting CAR T-cells, which would allow for an allogenic "off-the-shelf" product that could be ready for immediate infusion (Torikai et al., 2012; Valton et al., 2015). The genetically engineered universal allogeneic CAR T-cells could overcome some of the drawbacks of using the autologous CAR T-cells. Such allogenic universal CAR T-cells are generated from healthy donors to treat many patients and would be integrated with known clinical targeting moieties (such as monoclonal antibodies cetuximab, rituximab or trastuzumab) depending on the targeted cancer cells (Torikai et al., 2012). However, the major limitations that still prevent the clinical use of these allogenic universal CAR T-cells are the graft-versus-host disease (GVHD) that could cause rejection of the infused universal CAR T-cells by the patient (Shlomchik, 2007). The endogenous TCR in donor cells could recognize alloantigens of the recipient patient and allogeneic HLA molecules leading to GVHD and rapid rejection by the host immune system. However, with multiplex genomic editing technology the expression of endogenous TCRs of the donor T-cells could be ablated (Ren et al., 2017). Knocking down the expression of endogenous TCR through gene disruption using zinc finger nucleases (ZFNs), or transcription activator-like effector nucleases (TALENs) or CRISP/Cas9 technology would allow the delivery of allogeneic universal CAR T-cells without GVHD and with long persistence of CAR T-cells (Li and Zhao, 2017).

Universal allogeneic "off-the-shelf" CAR T-cells have been successfully used to treat two infants with relapsed refractory acute lymphocytic leukemia. T-cells from a healthy donor were genetically modified to produce CD19-CAR T-cells at the mean time the endogenous TCR of the cells were knocked out through the use of (TALENs) to eliminate alloreactivity response. Following the infusion of these universal CD19-CAR T-cells, the two infants responded well to the treatment and both proceeded to allogeneic stem cell transplantation (Qasim et al., 2017).

\section{Conclusions}

CAR T-cell cancer immunotherapy is a rapidly growing treatment modality that has proved impressive results both in research and in clinical trials, especially for hematological malignancies. FDA approval on August 2017 for the first CAR T-cell construct "Kymriah" is considered as a new era in cancer immunotherapy offering the ability to reprogram a patient's own immune cells to attack its own cancer cells. However, this rapidly developing technique still has considerable challenges that should be addressed for a wide clinical application for different cancer types.

Increasing the tumor targeting specificity by the selection of the appropriate antigen target moiety for CAR construct is the first and most important step during CAR T-cell construction. Moreover, this can reduce toxicity related to "on-tumor/ off-target" effect. The search for the ideal and unique tumor target for each tumor type is still under intense investigation.

Poor persistence of the infused genetically modified CAR $\mathrm{T}$-cells could result in week anti-tumor responses. However, the development of the new generations of CAR T-cells was able to overcome this drawback and provided high persistence and proliferation of CAR T-cells with increased cytokine secretion.

Although CAR T-cells therapies have shown encouraging preliminary results in solid tumors, the clinical data so far fail to meet the dreamed expectations. Therefore, extensive research is ongoing to address challenges of applying CAR T-cell therapy in solid tumor and several strategies are being suggested to enhance trafficking of CAR T-cells in the hostile tumor microenvironment and maximizing therapeutic efficacy.

Combining CAR T-cell therapy with other treatment modalities such as conventional chemotherapy or other immunotherapeutic modalities such as checkpoint inhibitors could provide promising synergistic effects in improving the anti-tumor responses.

The CAR T-cell technology is now in the process of commercialization at an acceptable cost with the ability to develop an effective universal "off-the-shelf" CAR T-cells generated from healthy donors.

\section{Conflicts of interests}

The authors have no conflicts of interests to disclose.

\section{Acknowledgements}

The authors would like to thank Dr. Tamer A. Mansour, Ph.D (University of California - Davis, United States) for the language and grammar editing of this manuscript. 


\section{References}

Beatty GL, Haas AR, Maus MV, Torigian DA, Soulen MC, Plesa G, et al. (2014). Mesothelin-specific chimeric antigen receptor mRNA-engineered $\mathrm{T}$ cells induce anti-tumor activity in solid malignancies. Cancer Immunol Res 2(2): 112-120. DOI: 10.1158/2326-6066.CIR-13-0170.

Bonifant CL, Jackson HJ, Brentjens RJ, Curran KJ (2016). Toxicity and management in CAR T-cell therapy. Mol Ther Oncolytics 3: 16011. DOI: $10.1038 /$ mto.2016.11.

Brentjens RJ, Davila ML, Riviere I, Park J, Wang X, Cowell LG, et al. (2013). CD19-targeted T cells rapidly induce molecular remissions in adults with chemotherapy-refractory acute lymphoblastic leukemia. Sci Transl Med 5(177): 177ra38. DOI: 10.1126/ scitranslmed.3005930.

Brentjens RJ, Rivière I, Park JH, Davila ML, Wang X, Stefanski J, et al. (2011). Safety and persistence of adoptively transferred autologous CD19-targeted T cells in patients with relapsed or chemotherapy refractory B-cell leukemias. Blood 118(18): 4817-4828. DOI: 10.1182/blood-2011-04-348540.

Brentjens RJ, Santos E, Nikhamin Y, Yeh R, Matsushita M, La Perle K, et al. (2007). Genetically targeted T cells eradicate systemic acute lymphoblastic leukemia xenografts. Clin Cancer Res 13(18): 5426-5435. DOI: 10.1158/1078-0432.CCR-07-0674.

Carpenito C, Milone MC, Hassan R, Simonet JC, Lakhal M, Suhoski MM, et al. (2009). Control of large, established tumor xenografts with genetically retargeted human $\mathrm{T}$ cells containing CD28 and CD137 domains. Proc Natl Acad Sci 106(9): 3360-3365. DOI: 10.1073/pnas.0813101106.

Cheadle EJ, Gornall H, Baldan V, Hanson V, Hawkins RE, Gilham DE (2014). CAR T cells: Driving the road from the laboratory to the clinic. Immunol Rev 257(1): 91-106. DOI: 10.1111/imr.12126.

Chen L, Flies DB (2013). Molecular mechanisms of T cell costimulation and co-inhibition. Nat Rev Immunol 13(4): 227-242. DOI: $10.1038 /$ nri3405.

Chmielewski M, Abken H (2015). TRUCKs: the fourth generation of CARs. Expert Opin Biol Ther 15(8): 1145-1154. DOI: $10.1517 / 14712598.2015 .1046430$.

Chmielewski M, Hombach AA, Abken H (2013). Antigen-specific T-cell activation independently of the MHC: Chimeric antigen receptor-redirected T cells. Front Immunol 4: 371. DOI: 10.3389/ fimmu.2013.00371.

Chmielewski M, Hombach AA, Abken H (2014). Of CARs and TRUCKs: Chimeric antigen receptor (CAR) T cells engineered with an inducible cytokine to modulate the tumor stroma. Immunol Rev 257(1): 83-90. DOI: 10.1111/imr.12125.

Chong EA, Melenhorst JJ, Lacey SF, Ambrose DE, Gonzalez V, Levine BL (2017). PD-1 blockade modulates chimeric antigen receptor (CAR)-modified T cells: Refueling the CAR. Blood 129(8): 1039-1041. DOI: 10.1182/blood-2016-09-738245.

Choo AY, Shedlock DJ, Muthumani K (2009). Electroporation of cytokines for cancer gene therapy. Cancer Biol Ther 8(22): 2123-2125. DOI: 10.4161/cbt.8.22.10083.

Chu Y, Hochberg J, Yahr A, Ayello J, van de Ven C, Barth M, et al. (2015). Targeting CD20+ aggressive B-cell non-hodgkin lymphoma by Anti-CD20 CAR mRNA-modified expanded natural killer cells in vitro and in NSG mice. Cancer Immunol Res 3(4): 333-344. DOI: 10.1158/2326-6066.CIR-14-0114.

Couzin-Frankel J (2013). Breakthrough of the year 2013. Cancer immunotherapy. Science 342(6165): 1432-1433. DOI: 10.1126/ science.342.6165.1432.

Davila ML, Riviere I, Wang X, Bartido S, Park J, Curran K, et al. (2014). Efficacy and toxicity management of $19-28 z$ CAR T cell therapy in B cell acute lymphoblastic leukemia. Sci Transl Med 6(224): 224ra25. DOI: 10.1126/scitranslmed.3008226.

Di Stasi A, De Angelis B, Rooney CM, Zhang L, Mahendravada A, Foster AE, et al. (2009). T lymphocytes coexpressing CCR4 and a chimeric antigen receptor targeting CD30 have improved homing and antitumor activity in a Hodgkin tumor model. Blood 113(25): 6392-6402. DOI: 10.1182/blood-2009-03-209650.

Di Stasi A, Tey SK, Dotti G, Fujita Y, Kennedy-Nasser A, Martinez C, et al. (2011). Inducible apoptosis as a safety switch for adoptive cell therapy. N Engl J Med 365(18): 1673-1683. DOI: 10.1056/ NEJMoa1106152.

Dotti G, Gottschalk S, Savoldo B, Brenner MK (2014). Design and development of therapies using chimeric antigen receptorexpressing T cells. Immunol Rev 257(1): 107-126. DOI: 10.1111/ imr.12131.

Farkona S, Diamandis EP, Blasutig IM (2016). Cancer immunotherapy: The beginning of the end of cancer? BMC Med 14: 73. DOI: 10.1186/s12916-016-0623-5.

Fisher J, Abramowski P, Wisidagamage Don ND, Flutter B, Capsomidis A, Cheung GWK, et al. (2017). Avoidance of ontarget off-tumor activation using a co-stimulation-only chimeric antigen receptor. Mol Ther 25(5): 1234-1247. DOI: 10.1016/j. ymthe.2017.03.002.

Gattinoni L, Finkelstein SE, Klebanoff CA, Antony PA, Palmer DC, Spiess PJ, et al. (2005). Removal of homeostatic cytokine sinks by lymphodepletion enhances the efficacy of adoptively transferred tumor-specific CD8+ T cells. J Exp Med 202(7): 907-912. DOI: $10.1084 / \mathrm{jem} .20050732$.

Gauthier J, Yakoub-Agha I (2017). Chimeric antigen-receptor T-cell therapy for hematological malignancies and solid tumors: Clinical data to date, current limitations and perspectives. Curr Res Transl Med 65(3): 93-102. DOI: 10.1016/j.retram.2017.08.003.

Gill S, June CH (2015). Going viral: Chimeric antigen receptor T-cell therapy for hematological malignancies. Immunol Rev 263(1): 68-89. DOI: 10.1111/imr.12243.

Gross G, Waks T, Eshhar Z (1989). Expression of immunoglobulinT-cell receptor chimeric molecules as functional receptors with antibody-type specificity. Proc Natl Acad Sci 86(24): 1002410028. DOI: $10.1073 /$ pnas.86.24.10024.

Grupp SA, Kalos M, Barrett D, Aplenc R, Porter DL, Rheingold SR, et al. (2013). Chimeric antigen receptor-modified T cells for acute lymphoid leukemia. N Engl J Med 368: 1509-1518. DOI: 10.1056/ NEJMoa1215134.

Hackett PB, Largaespada DA, Switzer KC, Cooper LJN (2013). Evaluating risks of insertional mutagenesis by DNA transposons in gene therapy. Transl Res 161(4): 265-283. DOI: 10.1016/j. trsl.2012.12.005.

Hartmann J, Schüßler-Lenz M, Bondanza A, Buchholz CJ (2017). Clinical development of CAR T cells-challenges and opportunities in translating innovative treatment concepts. EMBO Mol Med 9(9): 1183-1197. DOI: 10.15252/emmm.201607485.

Haso W, Lee DW, Shah NN, Stetler-Stevenson M, Yuan CM, Pastan IH, et al. (2013). Anti-CD22-chimeric antigen receptors targeting B-cell precursor acute lymphoblastic leukemia. Blood 121(7): 1165-1174. DOI: 10.1182/blood-2012-06-438002.

Hatfield SM, Kjaergaard J, Lukashev D, Schreiber TH, Belikoff B, Abbott R, et al. (2015). Immunological mechanisms of the antitumor effects of supplemental oxygenation. Sci Transl Med 7(227): 277ra30. DOI: 10.1126/scitranslmed.aaa1260.

Houot R, Schultz LM, Marabelle A, Kohrt H (2015). T-cell-based immunotherapy: Adoptive cell transfer and checkpoint inhibition. Cancer Immunol Res 3(10): 1115-1122. DOI: 10.1158/23266066.CIR-15-0190.

Jaspers JE, Brentjens RJ (2017). Development of CAR T cells designed to improve antitumor efficacy and safety. Pharmacol Ther 178: 83-91. DOI: 10.1016/j.pharmthera.2017.03.012.

John LB, Devaud C, Duong CPM, Yong CS, Beavis PA, Haynes NM, et al. (2013). Anti-PD-1 antibody therapy potently enhances the eradication of established tumors by gene-modified T cells. Clin Cancer Res 19(20): 5636-5646. DOI: 10.1158/1078-0432.CCR13-0458.

Jones BS, Lamb LS, Goldman F, Di Stasi A (2014). Improving the safety of cell therapy products by suicide gene transfer. Front Pharmacol 5: 254. DOI: 10.3389/fphar.2014.00254.

Junghans RP, Ma Q, Rathore R, Gomes EM, Bais AJ, Lo AS, et al. (2016). Phase I trial of anti-PSMA designer CAR T-cells in prostate cancer: Possible role for interacting interleukin 2-T cell pharmacodynamics as a determinant of clinical response. Prostate 76(14): 1257-1270. DOI: 10.1002/pros.23214.

Kenderian SS, Ruella M, Shestova O, Klichinsky M, Aikawa V, Morrissette JJ, et al. (2015). CD33-specific chimeric antigen receptor $\mathrm{T}$ cells exhibit potent preclinical activity against 
human acute myeloid leukemia. Leukemia 29(8): 1637-1647. DOI: 10.1038/leu.2015.52.

Lamers $\mathrm{CH}$, Sleijfer S, van Steenbergen S, van Elzakker P, van Krimpen B, Groot C, et al. (2013). Treatment of metastatic renal cell carcinoma with CAIX CAR-engineered T cells: clinical evaluation and management of on-target toxicity. Mol Ther 21(4): 904-912. DOI: 10.1038/mt.2013.17.

Lamers CH, Sleijfer S, Vulto AG, Kruit WH, Kliffen M, Debets R, et al. (2006). Treatment of metastatic renal cell carcinoma with autologous T-lymphocytes genetically retargeted against carbonic anhydrase IX: first clinical experience. J Clin Oncol 24(13): e20e22. DOI: $10.1200 / J C O .2006 .05 .9964$.

Li H, Zhao Y (2017). Increasing the safety and efficacy of chimeric antigen receptor T cell therapy. Protein Cell 8(8): 573-589. DOI: 10.1007/s13238-017-0411-9.

Li S, Tao Z, Xu Y, Liu J, An N, Wang Y, et al. (2018). CD33 specific chimeric antigen receptor $\mathrm{T}$ cells with different costimulators showed potent anti-leukemia efficacy and different phenotype. Hum Gene Ther 29(5): 626-639. DOI: 10.1089/hum.2017.241.

Lipowska-Bhalla G, Gilham DE, Hawkins RE, Rothwell DG (2012). Targeted immunotherapy of cancer with CAR T cells: achievements and challenges. Cancer Immunol Immunother 61(7): 953-962. DOI: 10.1007/s00262-012-1254-0.

Lo AS, Ma Q, Liu DL, Junghans RP (2010). Anti-GD3 chimeric sFv-CD28/T-cell receptor zeta designer T cells for treatment of metastatic melanoma and other neuroectodermal tumors. Clin Cancer Res 16(10): 2769-2780. DOI: 10.1158/1078-0432.CCR10-0043.

Louis CU, Savoldo B, Dotti G, Pule M, Yvon E, Myers GD, et al. (2011). Antitumor activity and long-term fate of chimeric antigen receptor-positive T cells in patients with neuroblastoma. Blood 118(23): 6050-6056. DOI: 10.1182/blood-2011-05-354449.

Maher J, Brentjens RJ, Gunset G, Rivière I, Sadelain M (2002). Human T-lymphocyte cytotoxicity and proliferation directed by a single chimeric TCR //CD28 receptor. Nat Biotechnol 20: 70-75. DOI: $10.1038 / \mathrm{nbt} 0102-70$.

Martyniszyn A, Krahl A-C, André MC, Hombach AA, Abken H (2017). CD20-CD19 bispecific CAR T cells for the treatment of B cell malignancies. Hum Gene Ther 28(12): 1147-1157. DOI: 10.1089/hum.2017.126.

Maude SL, Barrett D, Teachey DT, Grupp SA (2014). Managing cytokine release syndrome associated with novel T cellengaging therapies. Cancer J 20(2): 119-122. DOI: 10.1097/ PPO.0000000000000035.

Maus MV, June CH (2016). Making better chimeric antigen receptors for adoptive T-cell therapy. Clin Cancer Res 22(8): 1875-1884. DOI: 10.1158/1078-0432.CCR-15-1433.

Mayor M, Zeltsman M, McGee E, Adusumilli PS (2016). A regional approach for CAR T-cell therapy for mesothelioma: From mouse models to clinical trial. Immunotherapy 8(5): 491-494. DOI: 10.2217/imt-2016-0008.

Milone MC, Fish JD, Carpenito C, Carroll RG, Binder GK, Teachey D, et al. (2009). Chimeric receptors containing CD137 signal transduction domains mediate enhanced survival of $\mathrm{T}$ cells and increased antileukemic efficacy in vivo. Mol Ther 17(8): 14531464. DOI: $10.1038 / \mathrm{mt} .2009 .83$.

Minagawa K, Jamil MO, Al-Obaidi M, Pereboeva L, Salzman D, Erba HP, et al. (2016). In vitro pre-clinical validation of suicide gene modified anti-CD33 redirected chimeric antigen receptor T-cells for acute myeloid leukemia. PLoS One 12(2): e0172640. DOI: 10.1371/journal.pone.0166891.

Morgan R, Boyerinas B (2016). Genetic modification of T cells. Biomedicines 4(2): E9. DOI: 10.3390/biomedicines4020009.

Morgan RA, Yang JC, Kitano M, Dudley ME, Laurencot CM, Rosenberg SA (2010). Case report of a serious adverse event following the administration of $\mathrm{t}$ cells transduced with a chimeric antigen receptor recognizing ERBB2. Mol Ther 18(4): 843-851. DOI: $10.1038 / \mathrm{mt} .2010 .24$.

Morrow T (2017). Novartis's kymriah: Harnessing immune system comes with worry about reining in costs. Manag Care 26(10): 28-30.

Nishio N, Diaconu I, Liu H, Cerullo V, Caruana I, Hoyos V, et al. (2014). Armed oncolytic virus enhances immune functions of chimeric antigen receptor-modified T cells in solid tumors. Cancer Res 74(18): 5195-5205. DOI: 10.1158/0008-5472.CAN-14-0697.

O'Hara M, Stashwick C, Haas AR, Tanyi JL (2016). Mesothelin as a target for chimeric antigen receptor-modified $\mathrm{T}$ cells as anticancer therapy. Immunotherapy 8(4): 449-460. DOI: 10.2217/imt.16.4.

Parkhurst MR, Yang JC, Langan RC, Dudley ME, Nathan DA, Feldman SA, et al. (2011). T cells targeting carcinoembryonic antigen can mediate regression of metastatic colorectal cancer but induce severe transient colitis. Mol Ther 19(13): 620-626. DOI: $10.1038 / \mathrm{mt} .2010 .272$.

Pinthus JH, Waks T, Kaufman-Francis K, Schindler DG, Harmelin A, Kanety H, et al. (2003). Immuno-gene therapy of established prostate tumors using chimeric receptor-redirected human lymphocytes. Cancer Res 63(10): 2470-2476.

Porter DL, Levine BL, Kalos M, Bagg A, June CH (2011). Chimeric antigen receptor-modified $\mathrm{T}$ cells in chronic lymphoid leukemia. N Engl J Med 365: 725-733. DOI: 10.1056/NEJMoa1103849.

Pule MA, Savoldo B, Myers GD, Rossig C, Russell HV, Dotti G, et al. (2008). Virus-specific T cells engineered to coexpress tumor-specific receptors: Persistence and antitumor activity in individuals with neuroblastoma. Nat Med 14(11): 1264-1270. DOI: $10.1038 / \mathrm{nm} .1882$.

Pulè MA, Straathof KC, Dotti G, Heslop HE, Rooney CM, Brenner MK (2005). A chimeric T cell antigen receptor that augments cytokine release and supports clonal expansion of primary human T cells. Mol Ther 12(5): 933-941. DOI: 10.1016/j. ymthe.2005.04.016.

Qasim W, Zhan H, Samarasinghe S, Adams S, Amrolia P, Stafford S, et al. (2017). Molecular remission of infant B-ALL after infusion of universal TALEN gene-edited CAR T cells. Sci Transl Med 9(374): eaaj2013. DOI: 10.1126/scitranslmed.aaj2013.

Qin L, Lai Y, Zhao R, Wei X, Weng J, Lai P, et al. (2017). Incorporation of a hinge domain improves the expansion of chimeric antigen receptor T cells. J Hematol Oncol 10(1): 68. DOI: 10.1186/s13045-017-0437-8.

Ramos CA, Ballard B, Zhang H, Dakhova O, Gee AP, Mei Z, et al. (2017). Clinical and immunological responses after CD30-specific chimeric antigen receptor-redirected lymphocytes. J Clin Invest 127(9): 3462-3471. DOI: 10.1172/JCI94306.

Ren J, Liu X, Fang C, Jiang S, June CH, Zhao Y (2017). Multiplex genome editing to generate universal CAR T cells resistant to PD1 inhibition. Clin Cancer Res 23(9): 2255-2266. DOI: 10.1158/1078-0432.CCR-16-1300.

Ritchie DS, Neeson PJ, Khot A, Peinert S, Tai T, Tainton K, et al. (2013). Persistence and efficacy of second generation CAR T Cell against the LeY Antigen in acute myeloid leukemia. Mol Ther 21(11): 2122-2129. DOI: 10.1038/mt.2013.154.

Sadelain M (2017). CD19 CAR T Cells. Cell 171(7): 1471. DOI: 10.1016/j.cell.2017.12.002.

Scarfò I, Maus MV (2017). Current approaches to increase CAR T cell potency in solid tumors: Targeting the tumor microenvironment. J Immunother Cancer 5: 28. DOI: 10.1186/s40425-017-0230-9.

Sheen AJ, Sherlock DJ, Irlam J, Hawkins RE, Gilham DE (2003). T lymphocytes isolated from patients with advanced colorectal cancer are suitable for gene immunotherapy approaches. $\mathrm{Br}$ J Cancer 88(7): 1119-1127. DOI: 10.1038/sj.bjc.6600857.

Shirasu N, Kuroki M (2012). Functional design of chimeric T-cell antigen receptors for adoptive immunotherapy of cancer: Architecture and outcomes. Anticancer Res 32(6): 2377-2383.

Shlomchik DS (2007). Graft-versus-host disease. Nat Rev Immunol 7(5): 340-352. DOI: 10.1038/nri2000.

Srivastava S, Riddell SR (2015). Engineering CAR T-cells: Design concepts. Trends Immunol 36(8): 494-502. DOI: 10.1016/j. it.2015.06.004.

Stanculeanu DL, Daniela Z, Lazescu A, Bunghez R, Anghel R (2016). Development of new immunotherapy treatments in different cancer types. J Med Life 9(3): 240-248.

Tchou J, Wang LC, Selven B, Zhang H, Conejo-Garcia J, Borghaei H, et al. (2012). Mesothelin, a novel immunotherapy target for triple negative breast cancer. Breast Cancer Res Treat 133(2): 799-804. DOI: 10.1007/s10549-012-2018-4.

Teng MW, Kershaw MH, Moeller M, Smyth MJ, Darcy PK (2004). Immunotherapy of cancer using systemically delivered gene- 
modified human T lymphocytes. Hum Gene Ther 15(7): 699-708. DOI: $10.1089 / 1043034041361235$.

Torikai H, Reik A, Liu PQ, Zhou Y, Zhang L, Maiti S, et al. (2012). A foundation for universal T-cell based immunotherapy: $\mathrm{T}$ cells engineered to express a CD19-specific chimeric-antigen-receptor and eliminate expression of endogenous TCR. Blood 119(24): 5697-5705. DOI: 10.1182/blood-2012-01-405365.

Turtle CJ, Hay KA, Hanafi LA, Li D, Cherian S, Chen X, et al. (2017). Durable molecular remissions in chronic lymphocytic leukemia treated with CD19-Specific chimeric antigen Receptor-modified T cells after failure of ibrutinib. J Clin Oncol 35(26): 3010-3020. DOI: $10.1200 / J C O .2017 .72 .8519$.

Valton J, Guyot V, Marechal A, Filhol JM, Juillerat A, Duclert A, et al. (2015). A Multidrug-resistant engineered CAR T cell for allogeneic combination immunotherapy. Mol Ther 23(9): 1507-1518. DOI: $10.1038 / \mathrm{mt} .2015 .104$.

Wang C, Wu Z, Wang Y, Guon YL, Dai H, Wang X-H, et al. (2017). Autologous $\mathrm{T}$ cells expressing cd30 chimeric antigen receptors for relapsed or refractory hodgkin lymphoma: An open-label phase I trial. Clin Cancer Res 23(5): 1156-1166. DOI: 10.1158/10780432.CCR-16-1365

Wang X, Rivière I (2016). Clinical manufacturing of CAR T cells: Foundation of a promising therapy. Mol Ther Oncolytics 3: 16015. DOI: $10.1038 / \mathrm{mto} .2016 .15$.
Xu J, Tian K, Zhang H, Li L, Liu H, Liu J, et al. (2017). Chimeric antigen receptor- $\mathrm{T}$ cell therapy for solid tumors require new clinical regimens. Expert Rev Anticancer Ther 17(12): 1099-1106. DOI: 10.1080/14737140.2017.1395285.

Xu XJ, Tang YM (2014). Cytokine release syndrome in cancer immunotherapy with chimeric antigen receptor engineered $\mathrm{T}$ cells. Cancer Lett 343(2): 172-178. DOI: 10.1016/j.canlet.2013.10.004.

Yao X, Ahmadzadeh M, Lu Y-C, Liewehr DJ, Dudley ME, Liu F, et al. (2012). Levels of peripheral CD4(+)FoxP3(+) regulatory T cells are negatively associated with clinical response to adoptive immunotherapy of human cancer. Blood 119, 5688-5696. DOI: 10.1182/blood-2011-10-386482

Zhang C, Liu J, Zhong JF, Zhang X (2017). Engineering CAR T-cells. Biomark Res 5: 22. DOI: 10.1186/s40364-017-0102-y.

Zhou X, Di Stasi A, Tey SK, Krance RA, Martinez C, Leung KS, et al. (2014). Long-term outcome after haploidentical stem cell transplant and infusion of $\mathrm{T}$ cells expressing the inducible caspase 9 safety transgene. Blood 123(25): 3895-3905. DIO: 10.1182/ blood-2014-01-551671.

Zuccolotto G, Fracasso G, Merlo A, Montagner IM, Rondina M, Bobisse S, et al. (2014). PSMA-specific CAR-engineered T cells eradicate disseminated prostate cancer in preclinical models. PLoS One 9(10): e109427. DOI: 10.1371/journal.pone.0109427. 